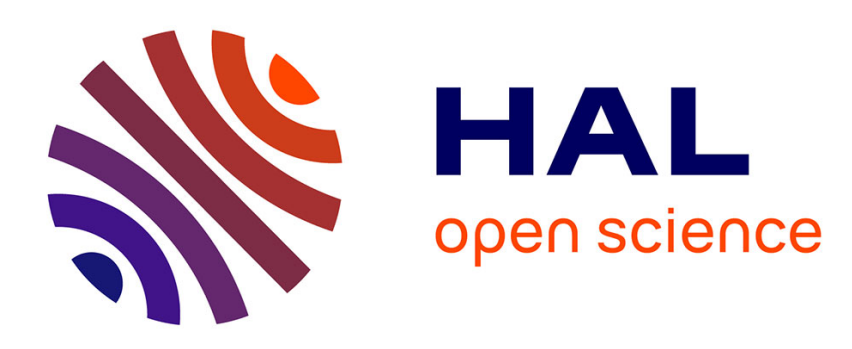

\title{
The use of cyclotrons as energy boosters for electrostatic accelerators
}

\author{
James B. Ball
}

\section{To cite this version:}

James B. Ball. The use of cyclotrons as energy boosters for electrostatic accelerators. Revue de Physique Appliquée, 1977, 12 (10), pp.1595-1600. 10.1051/rphysap:0197700120100159500 . jpa00244377

\section{HAL Id: jpa-00244377 https://hal.science/jpa-00244377}

Submitted on 1 Jan 1977

HAL is a multi-disciplinary open access archive for the deposit and dissemination of scientific research documents, whether they are published or not. The documents may come from teaching and research institutions in France or abroad, or from public or private research centers.
L'archive ouverte pluridisciplinaire HAL, est destinée au dépôt et à la diffusion de documents scientifiques de niveau recherche, publiés ou non, émanant des établissements d'enseignement et de recherche français ou étrangers, des laboratoires publics ou privés. 


\title{
THE USE OF CYCLOTRONS AS ENERGY BOOSTERS FOR ELECTROSTATIC ACCELERATORS
}

\author{
James B. BALL \\ Oak Ridge National Laboratory (*), Oak Ridge, Tennessee, U.S.A.
}

\begin{abstract}
Résumé. - On discute de l'utilisation de cyclotrons comme post-accélérateurs couplés à des accélérateurs electrostatiques. L'état actuel de différents projets est présenté ainsi que les caractéristiques des performances pour les différents choix de combinaison d'accélérateur.
\end{abstract}

\begin{abstract}
The use of cyclotron boosters to expand the energy capabilities of electrostatic accelerators is discussed. The present status of various projects is reviewed and the performance characteristics of possible choices for combining accelerators are presented.
\end{abstract}

The map of figure 1 illustrates part of the terrain inhabited by the accelerator user and hence by the accelerator builder. Although this plot emphasizes particle energy, the desires of the experimentalist have not been limited solely to this feature. The desire for beams of high intensity, high luminosity, and ease of energy variability has also been strong and the electrostatic accelerator has played a prominent role in research demanding all these characteristics.

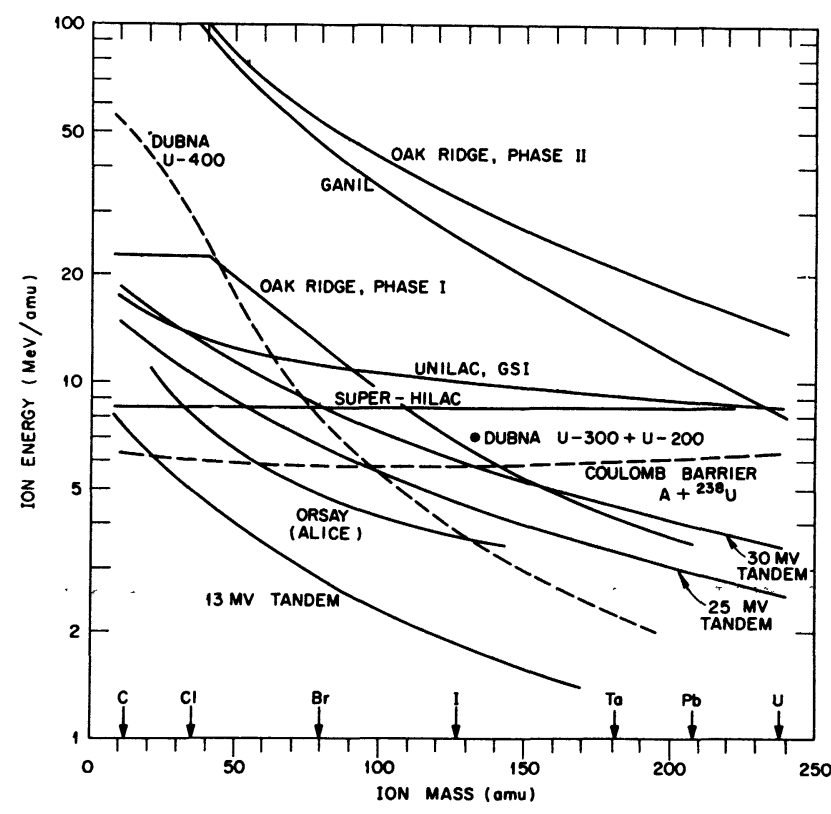

FIG. 1. - Ion energy performance capabilities of various operating and proposed accelerator facilities.

$\left(^{*}\right)$ Operated by Union Carbide Corporation for the US Energy Research and Development Administration.
One of the earliest limitations encountered by the electrostatic machines, however, was that of energy. We have seen the energies for the lightest particles pushed far out along the ordinate of this plot beyond the region shown here by a succession of cyclic, linear, and finally the large ring accelerators. For many years the electrostatic accelerator has dominated the research efforts pushing out along the other axis into the realm of macroscopic physics or heavy ion science. Again, all these same performance characteristics have been important and well provided by these machines. Now, however, with the virtual explosion of interest these past few years in all areas of heavy ion research we are again faced with increasing demands on accelerator performance. In particular, the demand has been strong to provide all ions with energy sufficient to overcome the Coulomb barrier for the heaviest targets.

What does this sort of a demand require of the electrostatic accelerator builder? A comparison of the performance of a $13 \mathrm{MV}, 25 \mathrm{MV}$, and $50 \mathrm{MV}$ Tandem is shown in figure 2. (These curves are calculated for the case of two strippers; a gas stripper in the terminal and a foil stripper one-third of the way down the high-energy tube. The contours shown represent an intensity of $10^{11} \mathrm{particles} / \mathrm{s}$ and assume a flux yielding $6 \times 10^{12}$ particles/s in the most probable charge state following the gas stripper. Actual charge states following both strippers have been selected to optimize the intensity/energy performance.)

Clearly, a $50 \mathrm{MV}$ Tandem accelerator would satisfy many of the present day requirements of heavy ion research. It is far from clear, however, that such a machine is economically practical. Present day costs for a complete Tandem accelerator system in the $13 \mathrm{MV}$ range will run on the order of 4 million dollars. For a Tandem in the $25 \mathrm{MV}$ class this will 


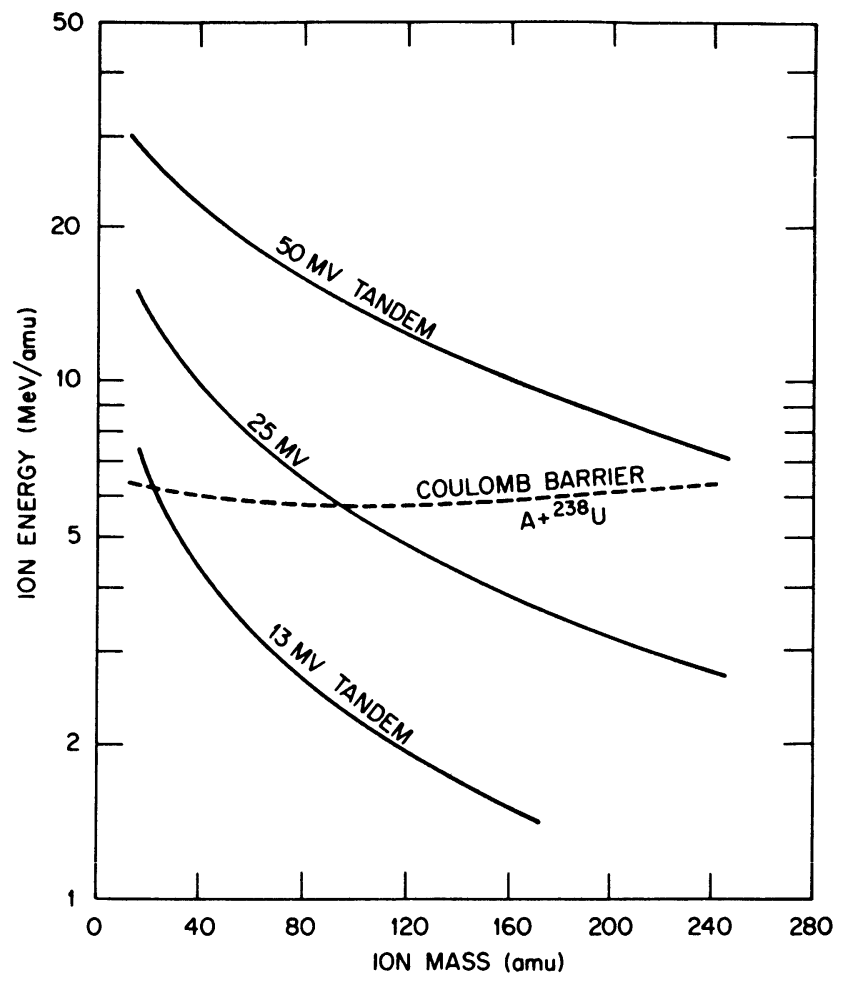

FIG. 2. - The ion energy-ion mass characteristics for three sizes of Tandem electrostatic accelerators. Two strippers are assumed (see text).

be more like 10 million dollars and a $50 \mathrm{MV}$ machine could easily exceed 40 million - just for the accelerator. So, it becomes necessary to examine more cost-effective methods of providing the desired performance goals.

Such an examination leads us to coupling accelerators together in various combinations. This approach opens up the exciting possibility of greatly improving performance of existing Tandem accelerators by adding a booster accelerator. This paper reviews some of the current activity in construction of cyclotron boosters and discuss some of the options that may present interesting future possibilities.

One example of the cyclotron booster is the project at Oak Ridge where our existing cyclotron (ORIC) is being modified for use as a booster for the new $25 \mathrm{MV}$ Tandem [1]. The schematic shown in figure 3 illustrates the principles involved in using a circular field machine as a booster. Capture of the ion into an acceleration orbit is accomplished by changing the ion charge with a stripping foil. In this case the beam from the Tandem is brought in through the inside of the $\mathrm{RF}$ resonator. An inflection magnet places the beam on an appropriate path so that the ions are bent by the fringing field of the cyclotron magnet and brought tangent to an acceleration orbit. This is the point where the stripper foil must be placed to provide the charge change needed to decrease the magnetic rigidity of the ion and put it in the appropriate orbit for acceleration.

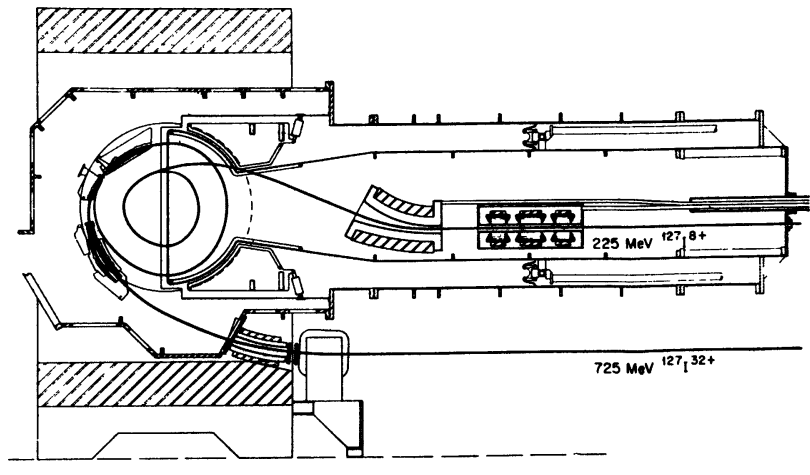

FIG. 3. - Schematic view of the ORIC operating as an energy booster for $127 \mathrm{I}$ ions from the $25 \mathrm{MV}$ Tandem.

In the figure, ${ }^{127} \mathrm{I}$ is used as an example. With the Tandem operating at $25 \mathrm{MV}$ on terminal, the most probable charge state for ${ }^{127}$ I passing through a gas stripper will be $8^{+}$. The energy out of the Tandem is thus $225 \mathrm{MeV}$. The most probable charge state for $225 \mathrm{MeV}$ I after passing through a carbon stripper is computed to be $32^{+}$. In this example, the parameters of the cyclotron are assumed set to accelerate this charge state. Note that the other charge states produced at the foil stripper are not in resonance and will be lost. Thus only some $20 \%$ of the injected beam will be boosted to the final energy. (This is essentially the same loss that would be experienced with a second stripper in the Tandem.) An additional beam loss, however, is introduced by the pulsed nature of the cyclotron. In order to maintain the high beam quality obtained from the electrostatic accelerator, the ions should be injected within a window of about $6^{\circ}$ of the cyclotron RF phase. In the case of ORIC this means that the DC beam of the Tandem must be bunched into pulses in the range of 1-2 ns width. Use of a double-drift harmonic beam buncher will provide $50-60 \%$ of the Tandem beam within this window thus reducing the beam only about a factor of 2 .

What do we gain from this coupling? From the standpoint of the cyclotron, we have gained considerable energy. The ion energy from a cyclotron, limited by the magnetic field, can be expressed as $E / A=K_{B} q^{2} / A^{2}$ where $q$ is the charge on the ion. (In the case of ORIC, $K_{B} \simeq 90$.) The internal Penning source of the cyclotron would be expected to produce I ions up to charge state around $8^{+}$. However, with I ions from the Tandem we can easily produce $32^{+}$, a factor of 4 higher charge, which yields a factor of 16 in energy! From the standpoint of the Tandem, we have taken a beam at $\sim 2 \mathrm{MeV} /$ nucleon and increased its energy to $\sim 6 \mathrm{MeV} /$ nucleon. In our particular case, with the $25 \mathrm{MV}$ Tandem we run out of sufficient energy to exceed the Coulomb barrier at about $A=90$. Using the ORIC as a booster extends this range up to about $A=150$. 
In order to cover the complete range of ion mass with energies above the Coulomb barrier, we are planning to add a larger, $K_{B}=400$, cyclotron booster [2]. The projected performance of this phase II was shown in figure 1 . The cyclotron design selected is based on the separated-sector concept and the proposed layout is shown in figure 4. A more

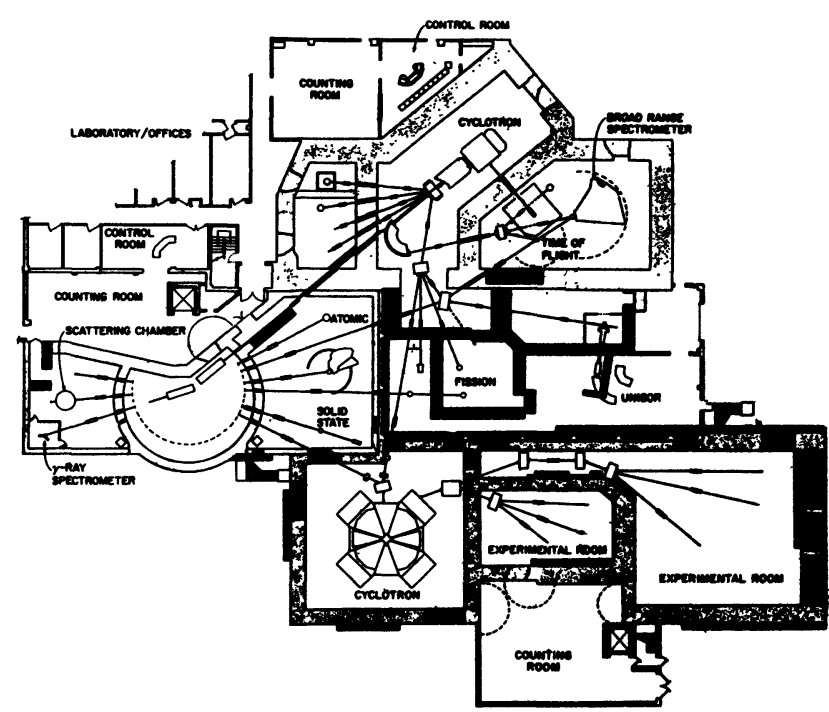

FIG. 4. - The Holifield Heavy Ion Research Facility at Oak Ridge. Phase II is the lower portion housing the separated-sector cyclotron and its associated experiment area.

detailed section of the machine in figure 5 shows the four magnet sectors, the two RF accelerating structures, and the injection and extraction elements. This machine operates in the same frequency range as ORIC so the bunching requirements on the

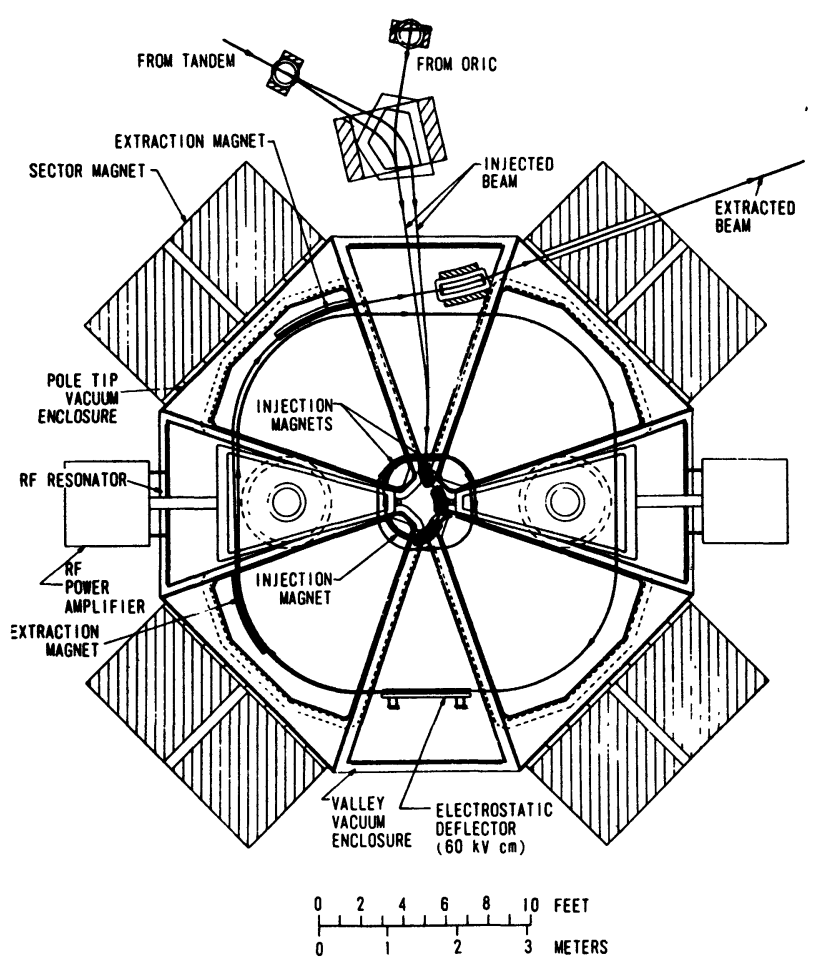

FIG. 5. - Plan view drawing of the phase II cyclotron.
Tandem are not changed. With this type of cyclotron booster, the stripping is done outside the machine and only the charge state of interest is injected and accelerated. Whereas injection into the circular field cyclotron is totally dependent upon the foil stripper, the separated-sector cyclotron offers complete flexibility in choice of strippers.

An example of such a separated-sector cyclotron booster is the VICKSI installation at Hahn-Meitner Institute [3]. The layout is shown in figure 6. Here a

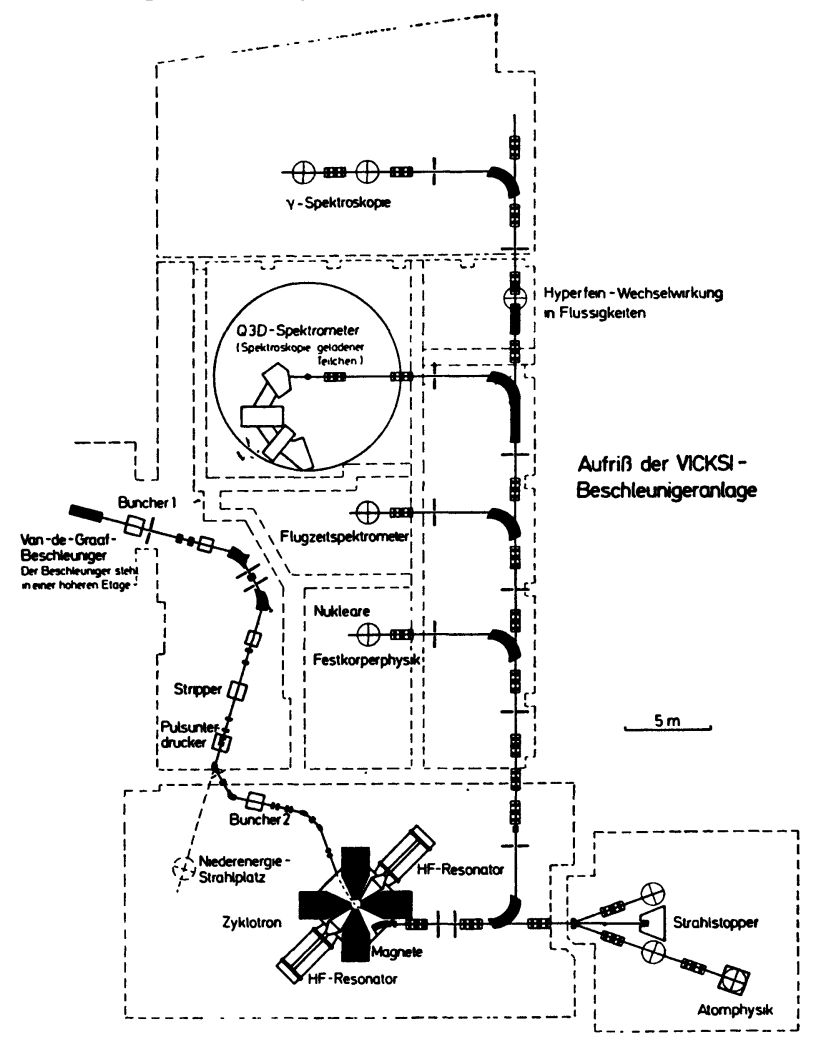

FIG. 6. - Layout of the VICKSI Facility at the Hahn-Meitner Institute.

$6 \mathrm{MV}$ single-ended electrostatic accelerator is used to inject a small $\left(K_{B}=120\right)$ booster. A picture of the cyclotron nearly completed is shown in figure 7. This facility, which will be used principally in the region of the ion masses up to $A=40$ is now beginning operation.

Another interesting example of combining a Tandem accelerator with a cyclotron booster is the project at Chalk River. A superconducting cyclotron with $K_{B}=500$ is being constructed as a booster for their 13 MV MP Tandem. The proposed layout for this facility is shown in figure 8. An interesting sidelight is that this configuration requires reversing the direction of acceleration in the MP Tandem from its present setup.

The major innovation here is the superconducting cyclotron. This novel concept is being developed in parallel at Chalk River, Michigan State University, and the University of Milan. The essential idea of these machines is to combine the high field technology developed for bubble chamber coils with the existing 


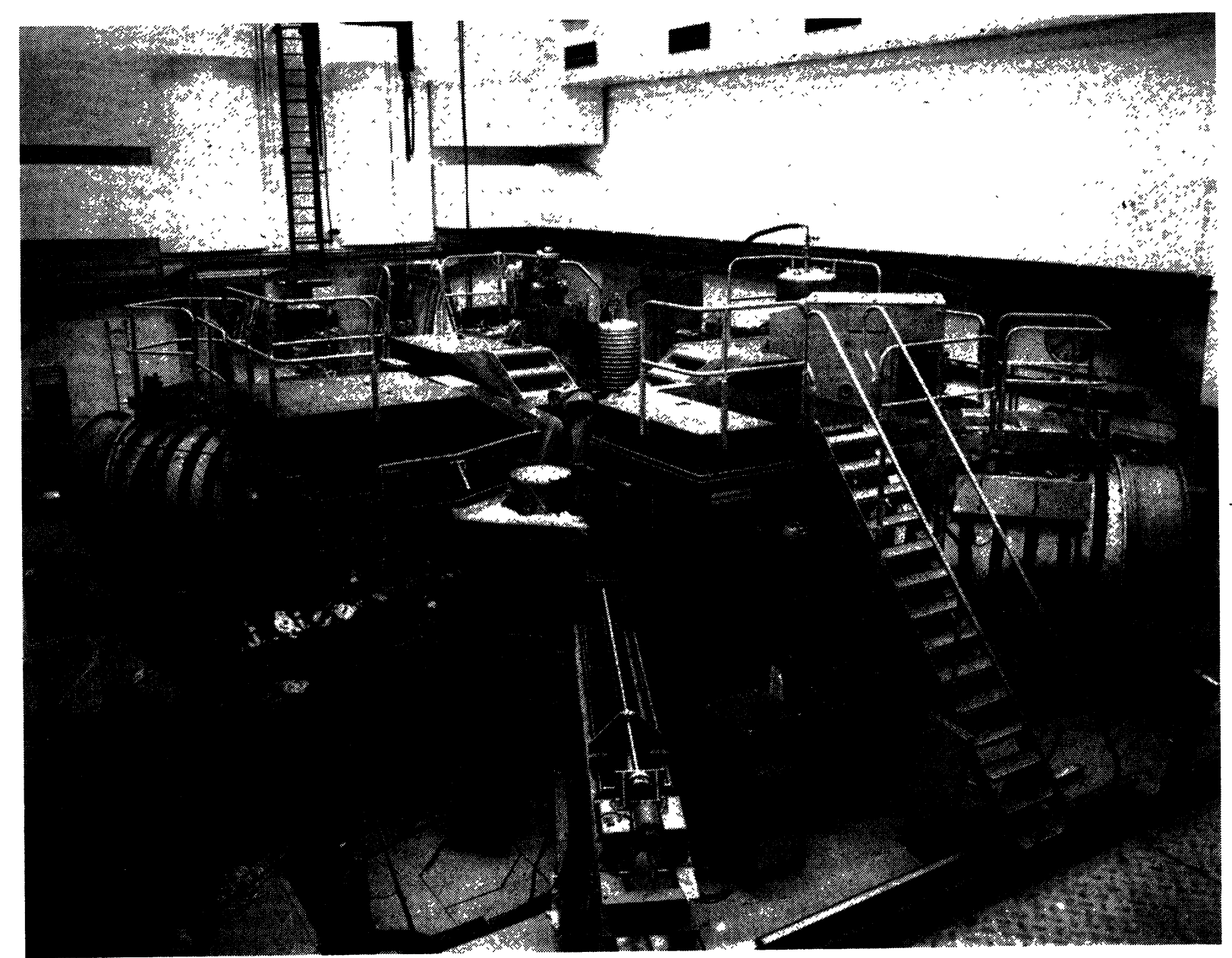

FIG. 7. - View of the VICKSI separated-sector cyclotron booster.

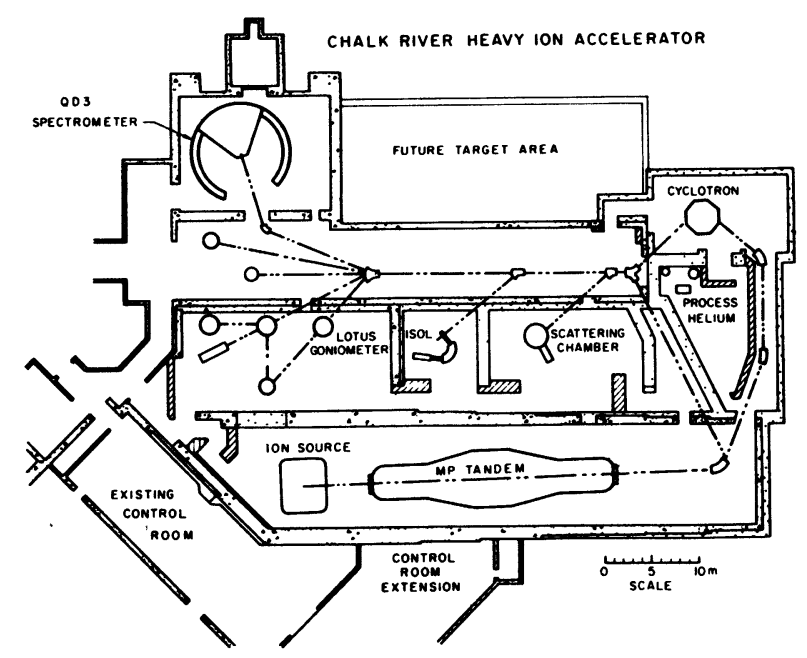

Fig. 8. - The Chalk River Nuclear Laboratories Tandem/superconducting cyclotron facility.

isochronous cyclotron technology. The actual superconducting elements are the main field coils with the remainder of the accelerator at room temperature. The coil designs of all three machines show strong similarities with the main coil divided into two sections to provide adjustment for first order field shaping by shifting current between windings. A cutaway drawing of the MSU magnet is shown in figure 9 and a picture of the yoke in figure 10 [4].

The obvious effect of using the high fields is the reduction in physical size with the accompanying

SUPERCONDUCTING CYCLOTRON MAGNET - K=500 MeV, $K_{F}=160 \mathrm{MeV}$

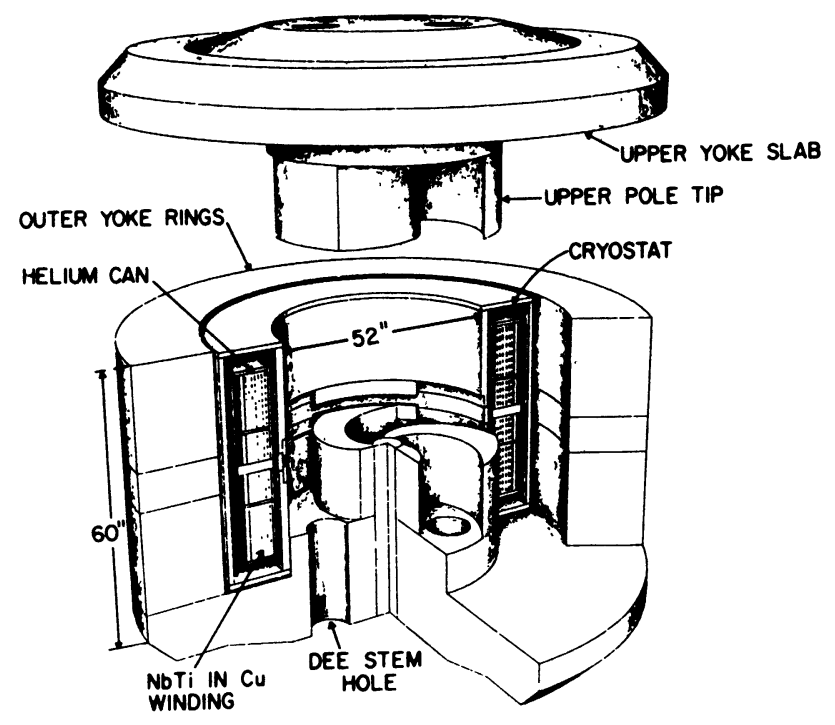

FIG. 9. - Schematic view of the Michigan State University superconducting cyclotron magnet. 


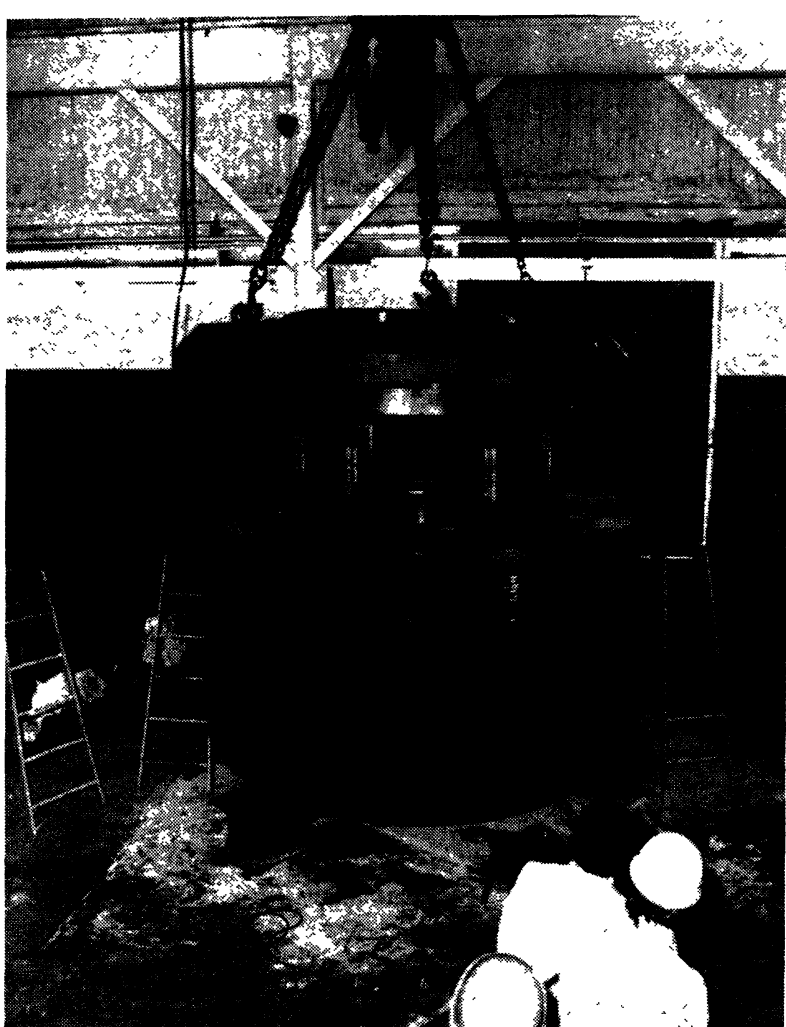

FIG. 10. - View of the MSU magnet yoke and cryostat.

reduction in cost. Average fields will be in excess of $40 \mathrm{kG}$-more than twice the field levels in conventional room temperature cyclotrons. An additional performance limitation on these machines introduced by the high fields has to do with the amount of variation of hill-to-valley field that can be obtained. This flutter and the hill spiral determines the focussing ability; the energy of a cyclotron also being limited by the equation $\frac{E}{A}=K_{\mathrm{F}} q / A$. The Chalk River design with four pole geometry will have a $K_{\mathrm{F}} \sim 100$ while the MSU and Milan designs employ a three pole configuration to obtain a higher focussing limit $K_{\mathrm{F}} \sim 160$. The result of this is that while the heavy mass ions are limited in energy by the magnetic field $\left(K_{B}\right)$, the lighter ions are limited by the focussing $\left(K_{\mathrm{F}}\right)$. For ions with $q / A$ of $1 / 2$, the maximum energy from the Chalk River booster will be $50 \mathrm{MeV} /$ nucleon. For the three sector machines this limit is $\sim 80 \mathrm{MeV} /$ nucleon. A plan view of the Chalk River design is shown in figure 11, showing the various injection and extraction elements [5].

To provide as large a turn spacing as possible, these machines will employ an accelerating electrode in each valley. Resonator frequencies are approximately four times those for the room temperature separated-sector machines which places increased demands on the accuracy of buncher phasing.

The superconducting cyclotron booster, like ORIC, is dependent on foil stripping inside the machine to accomplish injection. Note that the injected particle

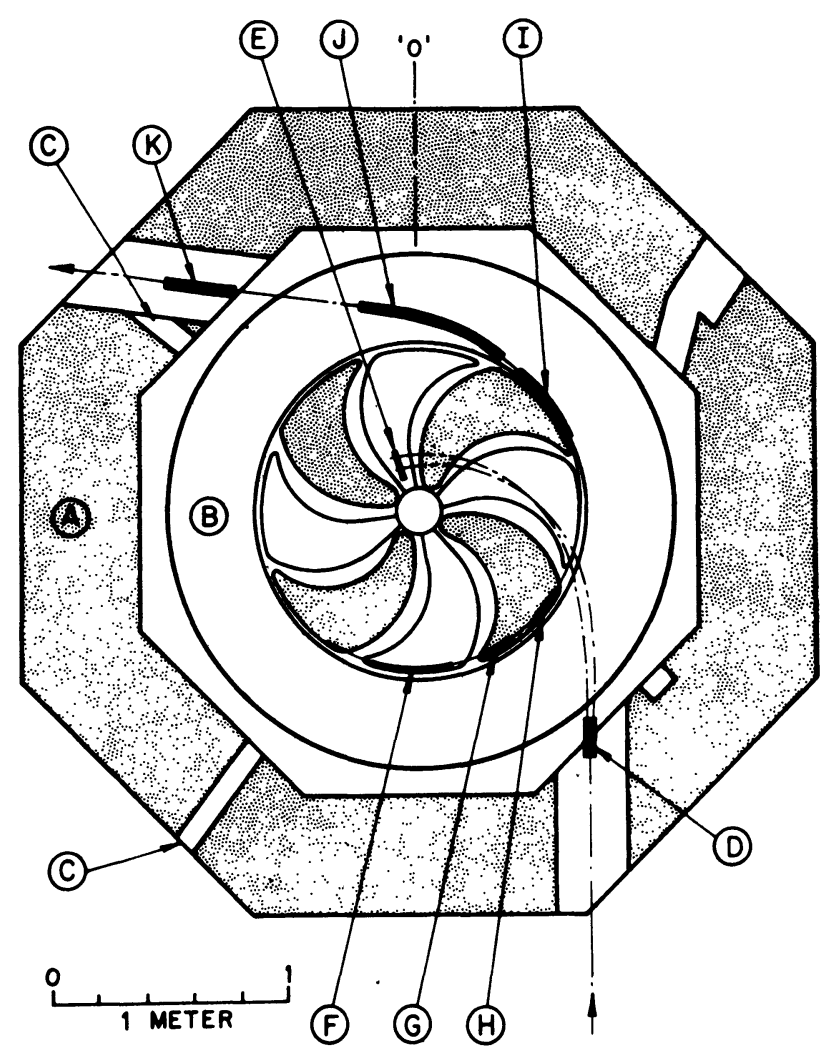

Fig. 11. - Plan view of the Chalk River superconducting cyclotron showing yoke and cryostat $(\mathrm{A}, \mathrm{B})$, injection magnet and stripper foil $(\mathrm{D}, \mathrm{E})$, and extraction elements $(\mathrm{F}-\mathrm{K})$.

must cut a large number of magnetic flux lines to reach the position of the stripper foil. (This was also true for the ORIC booster geometry.) This requires that the injected beam have a relatively large magnetic rigidity and puts a premium on obtaining beams from the Tandem with as high an energy and low a charge as possible. For many cases this is what dictates using a gas stripper in the Tandem and for the lighter ions it will be necessary, in some cases, to run with less than an equilibrium thickness of gas in the stripper. Typically charge changes at injection in circular field machines will need to be a factor of 2 or larger. As an example, for accelerating carbon ions the gas pressure in the stripper will have to be lowered to produce ions in charge state +2 or +3 from the Tandem at the highest terminal voltages. Preliminary results of studies at Chalk River and at Oak Ridge indicate that good yields of low charge states may be obtained readily by appropriate adjustment of gas pressure in the stripper canal.

All three of the groups studying superconducting cyclotrons are funded presently for prototype magnet studies. Both the Chalk River and MSU prototypes are full size, designed for conversion to operating cyclotrons. Proceeding on their present schedule, the Chalk River group would expect to be operational in 1980. The MSU machine is planned for an internal ion source but is built so that it may be converted to a booster if desired. The University of 
Rochester has proposed such a booster for their MP Tandem. The cyclotron study of the Milan group is aimed towards providing a booster for the XTU recently purchased for installation at Padua [6].

What are the considerations then for adding cyclotron boosters to Tandem accelerators? At Oak Ridge we continue to favor the separated-sector machine because of its proven performance and greatest operational flexibility. The major disadvantage of the separated-sector design is the rather inefficient use of iron and the resultant high cost of the magnet. Cost estimates for a large $(K=400)$ machine are in the range of 8 to 10 million dollars. One of the most appealing aspects of the superconducting cyclotron is that the cost of a machine with similar capabilities is only one-third to one-half this amount. It must be remembered, however, that while building a separatedsector machine can be approached as a rather straightforward design and construction project a superconducting cyclotron must, at this time, be approached as a development program.

Finally, what about the energy performance characteristics of various combinations? Figure 12 illus-

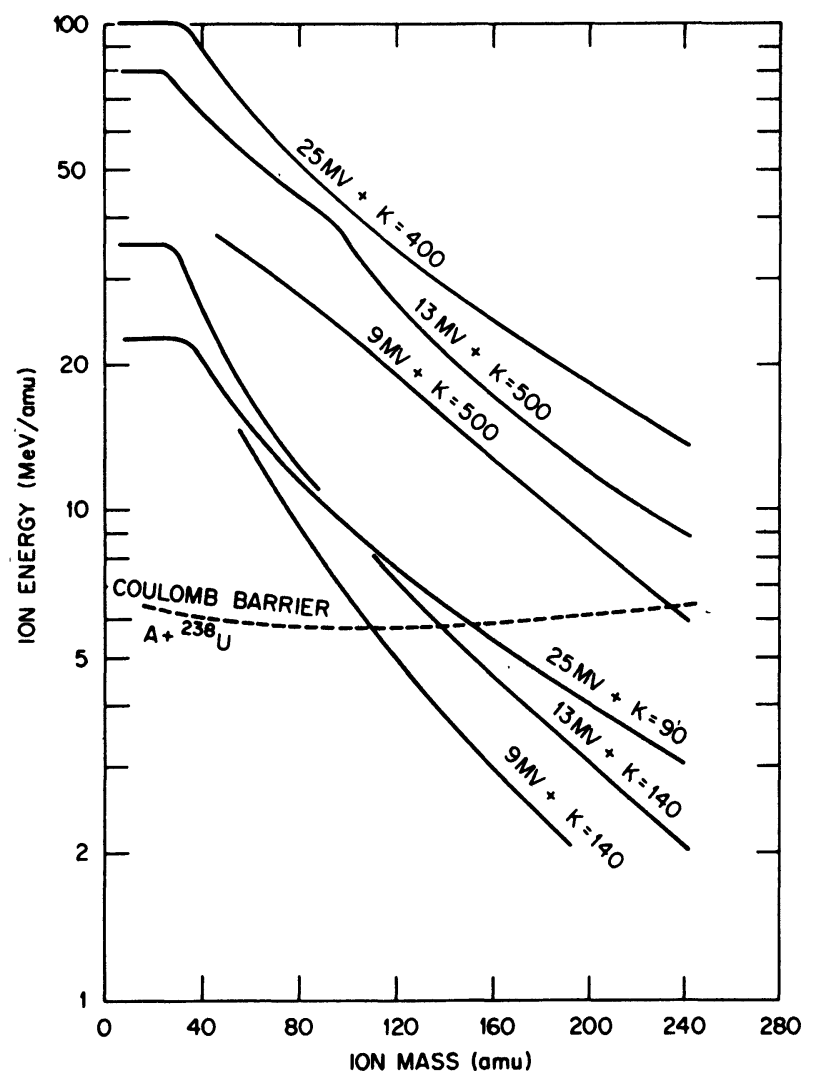

trates some of the possibilities. Besides the case of the Oak Ridge $25 \mathrm{MV}$ Tandem injecting ORIC $(K=90)$ and phase II $(K=400)$, also shown are a tandem in the $13 \mathrm{MV}$ class injecting a $K_{B}: K_{\mathrm{F}}=$ $500: 160$ superconducting machine. Also shown is the performance that could be achieved by adding such a booster to a tandem in the $9 \mathrm{MV}$ class. (These curves are calculated in a manner analagous to that used for figure 2. Gas stripping is assumed in the Tandem and foil stripping before or at injection in the booster. A bunching efficiency of $50 \%$ is assumed and the lines represent the $10^{11}$ part/s contour.) Since there are a number of existing cyclotrons in the $K=120$ to 160 range, two cases are included using a $K=140$ booster. Thus, one might also consider the possibility of upgrading some existing cyclotron facilities by providing Tandem injectors.

What about some of the other performance features? The high luminosity of the injected beam should be preserved by the booster cyclotron and the energy resolution, with $6^{\circ}$ bunching, should be $1: 1000$ or better. Ease of energy variability will continue to challenge the cyclotron builder but should see marked improvement as computer-based control systems come into use on the new machines.

Certainly the combination of Tandem injector and cyclotron booster provides a very effective means to cover, at reasonable cost and with good performance, the region of ion masses and energies sought by today's heavy ion researchers. In addition, the cyclotron as a booster brings with it a very attractive bonus. A machine capable of providing uranium ions at $10 \mathrm{MeV} /$ nucleon will, by the nature of its performance characteristics, provide the lighter masses at energies from 50 to $100 \mathrm{MeV} /$ nucleon. Such energies are presently the subject of increasing interest as speculation grows about the nature of heavy ion collisions at velocities exceeding the theoretical speed of sound in nuclear matter. It seems clear that these combined accelerator facilities will play a major role in the research of the coming years.

FIG. 12. - The ion energy-ion mass characteristics for various combinations of Tandem electrostatic injectors with cyclotron boosters.

\section{References}

[1] Jones C. M., Rev. Phys. Appl. 12 (1977).

[2] Martin J. A., et al., Proc. Part. Accel. Conf., Chicago, 1977, to be published.

[3] Maier K. H., Proc. 7th Int. Conf. on Cyclotrons and their Applications, Zurich, 1975, 68.
[4] BLosser H. G., et al., ibid., 585.

[5] Ormrod J. H., et al., ibid., 595, and Proc. Part. Accel. Conf., Chicago, 1977, to be published.

[6] ACerbi E., et al., Proc. Part. Accel. Conf., Chicago, 1977, to be published. 